\title{
AS TECNOLOGIAS UTILIZADAS NOS CURSOS OFERTADOS NO POLO DE EDUCAÇÃO A DISTÂNCIA DE GURUPI - TO
}

Maria Conceição Alves Soares* Rebeca S. Muceniecks Ferreira*

\section{Resumo}

Este trabalho concentra-se nas tecnologias utilizadas nos cursos de graduação em Física, Química, Matemática e Biologia, ofertados na modalidade a distância no Polo de EaD de Gurupi-TO, objetivando evidenciar o impacto do uso destas no processo ensino-aprendizagem nestes cursos. O trabalho foi de natureza qualitativa, de campo, com aplicação de questionário e análise estatística e de conteúdo. Com base neste estudo, é possível identificar que os recursos ou as ferramentas digitais que facilitam a interação entre os sujeitos são as disponíveis na internet e as redes sociais, mas indicam a necessidade de maior domínio dos alunos quanto às ferramentas do Moodle. A necessidade de uma maior interação entre os alunos e a ferramenta, focando o sucesso do ensino e consequente aprendizagem do aluno.

Palavras-chave: Educação a distância. Recursos tecnológicos. Tecnologias.

\section{INTRODUÇÃo}

A educação a distância tem sido colocada como uma das grandes possibilidades de expansão e acesso ao conhecimento na atualidade, principalmente nos locais mais distantes do Brasil, em regióes de difícil acesso. $\mathrm{O}$ censo de 2014 (INEP, 2014) indica que o número de alunos na modalidade a distância continua crescendo e contava com 1.341.842 em 2014, o que representa uma participação de 17,1\% do total de matrículas da educação superior. Enquanto o número de matrículas em cursos de graduação presenciais cresceu 5,4\% entre 2013 e 2014, na modalidade a distância, o aumento foi de $16,3 \%$.

Os cursos a distância tiveram o maior crescimento percentual registrado nas universidades, atingindo 17,8\%. Mas se, por um lado, tivemos 71,9\% do total de matrículas na graduação em 2014 na modalidade presencial em IES privadas, na modalidade a distância esta participação é ainda maior, 89,6\%. Ao comparar com dados de 2013, o número de ingressos nos cursos a distância cresceu 41,2\%; já nos cursos presenciais, o aumento foi de 7\%, o que é uma evidência de que os cursos a distancia estão em clara expansão. Um debate que se trava na educação diz respeito à qualidade e efetividade da aprendizagem em um curso realizado a distância e qual o tipo de aluno que consegue se adaptar a essa modalidade de educação.

Especialista em Educação a Distância com Habilitação em Tecnologias Educacionais pelo IFPR. E-mail: arickas2@yahoo.com.br

Doutora em Educação. Professora do Departamento de Teoria e Prática do Ensino - DTPEN da UFPR. E-mail: rebecamuceni@gmail.com

Instrumento: R. Est. Pesq. Educ., Juiz de Fora, v. 19, n. 1, jan./jun. 2017 
Nesse contexto, um dos problemas levantados é a interação. Todavia, acredita-se que os professores precisam buscar recursos tecnológicos e estratégias adequadas para integrá-la ao ensino dos cursos na modalidade $\mathrm{EaD}$, ou seja, é relevante conhecer os recursos e as estratégias usadas pelos professores nos cursos e seu impacto no processo de ensino.

Mesmo sabendo dos avanços tecnológicos, o processo de ensino continua tendo como base estratégias calcadas na educação presencial. $\mathrm{O}$ que buscamos com essa investigação foi verificar o impacto do uso dessas tecnologias no processo de ensino nos cursos de graduação do polo da Universidade Aberta do Brasil (UAB) da cidade de Gurupi, estado do Tocantins. O estudo foi realizado durante o mês de julho de 2016. Foram sujeitos dessa pesquisa professores e tutores das Licenciaturas em Química, Matemática, Física e Biologia.

Foi aplicado um questionário que coletou dados e informaçóes sobre o uso dos recursos tecnológicos que, na concepção dos docentes e tutores, são mais adequados para o processo de ensino de seus alunos. Os docentes utilizam todas as ferramentas disponibilizadas e qual o grau de importância que atribuem no momento do ensino? Dão importância a uma variedade de ferramentas que são disponibilizadas? Sabem definir o grau de importância de interação destas ferramentas?

A escrita da pesquisa é estruturada com a revisão bibliográfica, a metodologia e os instrumentos utilizados e a discussão dos dados, sendo finalizada com a conclusão da pesquisa.

\section{FundamentaÇão teórica}

\subsection{A EDUCAÇÃo A DiSTÂNCIA: ANÁlises E PER- SPECTIVAS}

A proliferação dos meios de comunicação marca a evolução da história da EaD no Brasil. A Lei 5.692/71 marcou o início legal de uma série de programas que tentavam fomentar a modalidade de EaD. Essas tentativas sofreram inserções do governo com ideologias que sustentassem o regime militar, que ocupava o poder no Estado.

O desafio era superar as resistências quanto ao regime ditatorial e a difusão dos modelos tecnológicos que estavam em pleno desenvolvimento na época. $\mathrm{O}$ desenvolvimento e o crescimento econômico foram os fatores que os militares usaram para a reforma educacional de 1972, principalmente no que se refere ao aumento das ofertas educacionais que formariam uma base mínima para o novo mundo industrializado que iniciava naquela época (MORAES, 2000).

A EaD trouxe consigo a perspectiva de uma política educacional mais abrangente no sentido de possibilitar o alcance de pessoas que não tinham o acesso ao conhecimento. Seria o caso, e por que não a solução, de atingir comunidades longínquas do meio urbano estruturado, como ocorreu, fazendo uma analogia, com a abertura econômica na década de 1990, quando houve uma pressão tão grande no contexto econômico que as pessoas passaram a manter contato com outras com quem nem imaginavam negociar para manter seus negócios competitivos.

O mesmo ocorreu com a educação. A pressão pelo processo de educaçáo continuada e permanente alavancou a discussão sobre o uso da tecnologia neste processo para derrubar barreiras geográficas e levar informações a populaçóes que não tinham em suas vidas diárias o momento de estudo, de pesquisa, ou seja, levar a elas o incentivo pela aprendizagem e demonstrar a necessidade que o conhecimento tinha para o sustento de suas famílias. Neste contexto, no início da década de 1990, com a Lei de Diretrizes e Base da Educação (LDB - Lei 9.394/1996), em seu Art. 80, no qual traz a $\mathrm{EaD}$ como oportunidade de acesso ao ensino e à aprendizagem. 
Segundo Torres (2001), o Relatório Delors salienta a ênfase dada à educação cidadã em que reafirma "a educação permanente" ou a "aprendizagem ao longo da vida" como eixo central da educação no século XXI. Este define a educação continuada como norte para a educação no século XXI, tendo o objetivo de construir uma comunidade educativa perene. Isto é, a educação incorpora para si diversas formas de aprendizagem, galgando identificar todo tipo de aprendizagem tanto no meio interno quanto no meio externo à escola.

\subsection{Histórico E CONCEITOS}

A $\mathrm{EaD}$ tem seus fundamentos baseados em modelos econômicos e sociais fordistas e pós-fordistas (BELLONI, 1999), influenciando no processo de criação de modelos e práticas na educação a distância. Em Peters (1983, p. 157):

\begin{abstract}
Educação/Ensino a Distância (FERNUNT ERRECHT) é método racional de partilhar conhecimento, habilidades e atitudes, através da aplicação da divisão do trabalho e de princípios organizacionais, tanto quanto pelo uso extensivo de meios de comunicação, especialmente para o propósito de reproduzir materiais técnicos de alta qualidade, os quais tornam possível instruir um grande número de estudantes ao mesmo tempo, enquanto esses materiais durarem. É uma forma industrializada de ensinar e aprender.
\end{abstract}

Nas últimas décadas, observa-se que as rápidas mudanças ocorridas no mercado trazem à tona, de forma mais contundente, a discussão do modelo fordista e pós-fordista. Observa-se que o modelo pós-fordista não entrega o produto, e sim fornece os meios para que o aluno possa construir e participar do processo de aprendizado com base nas suas próprias experiências.

Conceituar a $\mathrm{EaD}$ tem sido um desafio, pois há diferentes concepçóes e definiçóes terminológicas precisas que divergem em aspectos peculiares ao ambiente em que está empregada a EaD. Para Peters
(1983), a EaD é consequência da era industrial. Moore e Kearsley (1996, p. 2) definem como:

É o aprendizado planejado que normalmente ocorre em lugar diverso do professor e como consequência requer técnicas especiais de planejamento de curso, técnicas instrucionais especiais, métodos especiais de comunicaçáo eletrônica ou outros, bem como estrutura organizacional e administração específica (MOORE; KEARSLEY,1996, p. 2).

Este é um conceito abrangente e que consegue agregar todas as características e necessidades da EaD.

\subsection{Pontos relevantes na EaD e a tecno- LOGIA NECESSÁRIA}

Convém destacar que um êxito na modalidade de $\mathrm{EaD}$ é o rompimento de barreiras culturais, de línguas, de espaço geográfico, de tempo, assim como dinamiza o processo de ensino-aprendizagem. Entretanto, discutese qual o papel da educação frente às diversas inovaçóes tecnológicas, pois a contribuição que a tecnologia oferece ao processo de ensino é fator indiscutível para a qualidade no que se refere aos meios de obter informaçóes de todos os lugares.

Neste aspecto, da operacionalidade, a educação a distância constitui-se um conjunto de conhecimento que toma os pensamentos científicos do meio e utiliza todas as variáveis a seu redor, projetando-as na prática do ensino, e a responde de forma a alcançar os objetivos no contexto sócio-histórico de determinada localidade. Existe a preocupação com a prática do ensino em meio a práticas sociais, globais e que, inserindo as teorias da comunicação e o manuseio de novas tecnologias, por sua vez, a abordagem do estar unidos virtualmente vem explorar a potencialidade de interação que a internet proporciona através da comunicação multidimensional, aproximando assim emissores dos receptadores, permitindo que estes sejam instigados a criarem condiçóes de aprendizagem e cooperação, por meio de 
recursos como: chat, fórum, jogos educativos, e-mail e material download.

Uma questão muito discutida nesse processo é a separaçáo do professor e do aluno na relação espaço e tempo; porém, convém abordar que o objetivo não é o distanciamento desses dois atores do processo e, sim, diminuir ou até mesmo superar a barreira da distância, tornando o aprender uma ponte para o conhecimento de outras pessoas de outras realidades.

A metodologia de aulas presenciais não se constitui um obstáculo quando o prisma do processo é visto como um fator estimulador para a aprendizagem. Ou seja, o controle da aprendizagem acaba sendo realizado mais intensamente pelo aluno do que pelo professor. Um ponto importante na educação a distância é a interação de quem aprende e o objeto do saber. Abreu (1998, p. 26) preceitua que "o paradigma do ensino fundamentou a escola de hoje na função de difundir o conhecimento elaborado, baseado em um legado humanista, no qual o professor era o dono do saber e deveria repassá-lo ao aluno".

$\mathrm{O}$ processo de ensino-aprendizagem em EaD não tem uma teoria própria que possa ser denominada teoria de aprendizagem em EaD. Ela se respalda em várias teorias para embasar seu processo de ensinoaprendizagem. O modelo tradicional tende a ficar obsoleto em relação à educação ao longo da vida, e será uma prerrogativa de todo o cidadáo e um dever do poder público instituir o ensino para as populaçôes que estâo fora da simetria dos investimentos públicos.

As preocupações com os métodos e as concepções em EaD vão além da verificação das características mais comuns do seu processo com a de uma determinada teoria. Essa está em construir um conceito de métodos e concepçóes que embasem os projetos de $\mathrm{EaD}$. O construtivismo pode ser uma ferramenta para este desafio quando ele proporciona o aprender fazendo com conteúdos problematizadores.
Utilizando de conteúdos conflitantes, o aluno se sentirá provocado, tornando-se um estímulo para que sua aprendizagem seja mais significativa. Os demais atores desse processo também necessitam ser estimulados para criarem um ambiente confiável e colaborativo e façam do uso da tecnologia sua estratégia metodológica mais importante, quando esta é mero recurso transmissor de informaçóes.

Delors (2000) indica que os alicerces da educação são: aprender a conhecer, ou seja, obter os instrumentos necessários à compreensão e ao domínio do conhecimento; aprender a fazer, para agir dentro do meio, conciliando os saberes técnicos com os sociais; aprender a viver juntos, de forma a ser um indivíduo ativo no seu meio e conhecedor de sua história; aprender a ser, integrando os três alicerces anteriores e não desvalorizando nenhuma potencialidade de cada indivíduo, seja ela física, social, cognitiva e emocional.

O cerne dessa discussão é entender que a educação é um processo complexo e que cada nova mudança no quadro sócio-político-econômico mundial afeta o repassar de informaçóes e a aquisição de saber passa a ter outros objetivos, e náo táo somente o de informar. $\mathrm{A} \mathrm{EaD}$ precisa se utilizar de meios que façam da interatividade e da comunicação seus dois principais requisitos para construção da aprendizagem colaborativa e possam auxiliar no novo paradigma educacional que o mundo globalizado propóe.

A aprendizagem colaborativa implica em uma aprendizagem em tempo real, onde os participantes estão em um ambiente de total interação e juntos estão acumulando conhecimentos e registrando seus pensamentos com a permissáo dos demais, o que difere da cooperação. Esta é a divisão das tarefas do aprendizado, na qual cada participante é responsável pela resolução de uma parte do problema e assim constrói a solução em um todo. 
O aluno de EaD é o mentor e articulador do seu aprender. Ele organiza seu tempo e momento de estudar, é um ser ativo no processo, daí a significação do material impresso ser confeccionado de forma a permitir esse interesse de desenvolver as funçôes cognitivas do discente. Para que ele possa aprender a aprender de maneira independente de um professor transmissor de informações.

Esse material deve procurar sempre adequar-se ao meio do aluno e deve ser feito de forma modular, permitindo a inclusão de situaçóes do dia a dia para enriquecimento do aprendizado. Toda a estrutura pede um pré-diagnóstico do ambiente, de forma a empregar a tecnologia e os meios adequados àquela realidade. O objetivo é fazer desses recursos uma estratégia metodológica de suporte e apoio ao aluno, ou seja, escolher o meio que garanta a comunicação e a interaçáo dos atores do processo.

A proposta da $\mathrm{EaD}$ é criar um ambiente de aprendizagem que garanta os mesmos fatores de relacionamento encontrados na aprendizagem presencial, pois isso contribui para estreitar os requisitos que estão intrínsecos ao processo de comunicação. Neste processo, o professor de $\mathrm{EaD}$ tem que permitir o diálogo no qual possibilite ao aluno disponibilizar intervençóes no processo de ensino-aprendizagem.

O desafio é manter a comunicação e não deixar o antigo transmissor de informação dominar a metodologia da educação, isto é, o novo modelo aspira por métodos facilitadores da aprendizagem e tendo o aluno como um construtor do seu próprio conhecimento, como já comentado anteriormente.

Cirigliano (apud LANDIN, 1997) indica algumas características do professor de EaD: ter o domínio de técnicas de tutoria, seja de forma presencial ou a distância, contribuir para que o aluno interaja no processo, inserir informações do seu meio, dinamizar as aulas com a utilização de recursos e métodos específicos para determinada localidade e para cada perfil de aluno. Para este, devem ser oferecidos todos os mecanismos possíveis para que ele desenvolva seu pensamento reflexivo.

A EaD tem, em sua trajetória, passado por diversos obstáculos e vem demonstrando resultados que permitem analisar sua permanência no processo de educação, seja básica, superior ou de pós-graduação, como ferramenta alternativa para a melhoria do sistema educacional no Brasil. A EaD, além de atingir a milhares de pessoas que não tiveram ou não têm acesso à educação, proporciona também um meio para o desenvolvimento econômico de localidades à margem das políticas públicas brasileiras.

Dentro dessa nova realidade, faz-se necessária a busca por uma nova reflexão no processo educativo, em que a escola passe a vivenciar essas transformaçóes de forma a beneficiar suas açóes, podendo buscar novas formas didáticas e metodológicas de promoção do processo ensino-aprendizagem. Sobre isso, Moran (2004) afirma que o campo da educação está muito pressionado por mudanças, assim como acontece com as demais organizaçóes. Percebe-se que a educação é o caminho fundamental para transformar a sociedade.

A escola precisa rever seu papel no aprimoramento da sua prática educativa de forma a adequar sua prática pedagógica ao momento atual e, principalmente, colocar-se na posição de organização principal e mais importante na evolução dos princípios fundamentais de uma sociedade. Cumprindo, assim, sua função transformadora e idealizadora de conhecimentos científico-filosóficos, pautando o resultado de suas açóes em saber concreto.

Winner (2004) afirma que os estudantes de hoje sabem tanto mais que os de outros tempos, porém adquirem seu conhecimento em hipertextos, CD-ROM, enciclopédias, páginas web etc. E têm, portanto, uma forma particular de organizar os dados e compartilhar 
com os outros. Esse fato é um simples expoente da realidade cultural que vive grande parte da humanidade e que se distancia notoriamente daquela em que a geração adulta foi educada. Os educandos de hoje têm enorme capacidade de transitar por diversos mundos ao mesmo tempo, o que torna um desafio para educadores e sociedade, que devem estar atentos às mutaçóes culturais que fazem parte da vida dos alunos. Torna-se essencial dar aos educandos possibilidades de construir seu próprio projeto de vida, dentro de seus horizontes.

É perceptível que o saber científico e a busca pelo conhecimento têm fugido do interesse da sociedade em geral, pois a atualização das informaçóes tem ocorrido de forma acessível a todos os segmentos, satisfazendo, de uma forma geral, aos interesses daqueles que as buscam. A escola, nesse contexto, tem por opção repensar suas açóes e o seu papel no aprimoramento do saber e, para isso, uma reflexão sobre seus conceitos didáticometodológicos precisa ser feita, de forma a adequar-se ao momento atual e, principalmente, colocar-se na postura de organização principal e mais importante na evolução dos princípios fundamentais de uma sociedade. Dowbor (1998, p. 259), sobre essa temática, diz que

[...] será preciso trabalhar em dois tempos: o tempo do passado e o tempo do futuro. Fazer tudo hoje para superar as condiçóes do atraso e, ao mesmo tempo, criar as condiçóes para aproveitar amanhã as possibilidades das novas tecnologias.

A realidade dos alunos é cercada por novas linguagens, novas relaçôes entre as pessoas, modificando o tempo e o espaço tradicionais. Com isso, estão surgindo múltiplas trocas provenientes do mundo da comunicação que consequentemente desencadeiam transformações culturais e abrem espaços para gerar novas formas de conhecimento na sociedade da informação.

Acerca disso, Moran (2004) ressalta que o conhecimento não é fragmentado, mas interdependente, interligado, interssensorial. Conhecer significa compreender todas as dimensóes da realidade, captar e expressar essa totalidade de forma cada vez mais ampla e integral. Conhecemos mais e melhor conectando, juntando, relacionando, acessando o nosso objeto de todos os pontos de vista, por todos os caminhos, integrando-os da forma mais rica possível.

Os projetos têm considerado importante a capacitação de professores para o uso das novas tecnologias como instrumento valioso na transformação da sociedade, conforme é bem enfocado em Brasil (1988, p. 138):

\footnotetext{
A escola faz parte do mundo e, para cumprir sua função de contribuir para a formação de indivíduos que possam exercer plenamente sua cidadania, participando dos processos de transformaçáo e construção da realidade, deve estar aberta e incorporar novos hábitos, comportamentos, percepçóes e demandas.
}

Os anos 1990 apresentam-se com um grande movimento, que ainda se encontra em plena expansão, nas escolas públicas brasileiras, com experiências e pesquisas, o qual, acredita-se, é de suma importância: o movimento da internet na educação. Com a internet abrem-se imensas fronteiras que ainda necessitam ser exploradas e compreendidas pelos professores e educandos em um trabalho compartilhado.

\subsection{Desafios, Características, vantagens E DESVANTAGENS DA EAD}

O mundo globalizado pressupóe agilidade, segurança, qualidade e comprometimento com o produto e/ou serviço; neste caso específico, com a educação. Não há mais tanto tempo disponível para qualificar ou requalificar, no entanto, o pouco tempo é o fator que estimula a sociedade a buscar mais conhecimento sem, entretanto, deixar suas atividades profissionais à parte para alcançar este saber almejado. 
A era da informação vivida atualmente nos coloca em situações de aprendizagem que superem as barreiras do modelo tradicional de ensino, mesmo por que esse modelo não se mostra capaz de atender à demanda que a cada dia cresce de forma geométrica.

O papel da educaçáo a distância pode ser uma estratégia política de ensino se a legislação reconhecer a amplitude de oportunidade que este modelo traz para a educação ao longo da vida, tanto no que tange às exigências do mercado de trabalho como na construçáo da cidadania. Um outro ponto a ser considerado é que a educação a distância permite que o aluno continue no seu meio cultural e natural e prevaleça das suas experiências para o seu aprendizado.

O maior desafio da modalidade de educação a distância está em manter a qualidade do processo com a utilizaçáo adequada da tecnologia para o desenvolvimento de procedimentos metodológicos consistentes, buscando uma proposta de ensino eficaz, e averiguar como a não interatividade entre professor e aluno pode interferir ou náo no processo ensinoaprendizagem. Porém, o ponto crucial da $\mathrm{EaD}$ é incorporar a esta modalidade o sentido democrático do acesso ao saber e estar vigilante nas variáveis para delimitar o espaço da EaD. A importância dessa inovaçáo educacional pode estar relacionada ao dizer de Peter Drucker: "o reator da Economia moderna não é a fazenda, não é a fábrica, não é o banco. É a escola”.

\subsubsection{Características}

A EaD apresenta várias características e citaremos as destacadas por Desmond Keegan (apud LANDIM, 1997):

A separação do professor e do aluno, no que se refere ao fator tempo e espaço, e a influência de uma organização educacional que a distingue do ensino privado;
Utilização de meios técnicos impressos, para haver a interação professor e aluno, oferecendo o conteúdo educativo do curso;

Prover o programa de mecanismo que possa possibilitar uma comunicação bidirecional;

$\mathrm{O}$ ensino aos alunos de forma individual e ocasionalmente em grupos, com a intenção de encontros com propósitos didáticos e de socialização;

A apresentação de uma forma mais industrializada de educação, baseada no fundamento de que a o ensino a distância se caracteriza por: divisão de trabalho, mecanização, automação, aplicação de princípios organizativos, controle científico, objetividade do ensino, produção massiva, concentração e centralização.

O processo educativo de ensino a distância apresenta uma constante de características identificadas no processo, como: separação do aluno e professor pelo tempo e espaço; canal de comunicação por meio do uso de tecnologias; necessidade de uma estrutura organizacional complexa para atender às expectativas do discente e para que o processo não cause frustraçóes; e forma de aprendizagem é autodidata, em que o aluno é seu próprio termômetro de cobrança.

A importância da informação no aprendizado é crucial no modelo de $\mathrm{EaD}$ tanto quanto no modelo tradicional, é preciso criar a cultura de aprender a manusear as informaçóes e o conhecimento para que se possa utilizá-lo em nosso contexto pessoal, afetivo, intelectual, político e econômico, sempre atento às peculiaridades do ambiente. Desta forma, este conhecimento se torna um fator transformador de comportamentos e atitudes, redefinindo hábitos e valores.

O Brasil é um país sedento de conhecimento e a $\mathrm{EaD}$ pode representar o canal que preencherá esta lacuna, a exemplo de outros países, como Inglaterra e China, que investiram neste processo e hoje colhem frutos observáveis no seu quadro sociopolítico e cultural. Isso ocorreu pois a metodologia de $\mathrm{EaD}$ foi planejada e trabalhada de forma específica por meio de seus 
planos curriculares, ajustamentos e heterogeneidade dos discentes.

Niskier (1999, p. 83), define precisamente o que caracteriza a EaD: "a educação a distância tem a vantagem adicional de estimular a responsabilidade pessoal. Quem a procura sabe por que o faz, criando-se dessa forma uma nova ética de educação".

\subsubsection{Vantagens E Desvantagens}

As vantagens do processo de $\mathrm{EaD}$, segundo Landim (1997, p. 34), são:

\begin{abstract}
Abertura: apresentando as características de reduzir as barreiras para o acesso ao nível de estudos e cursos; amplitude maior na oferta de curso; abrem espaços para pessoas que não tiveram a oportunidade de frequentar o ensino tradicional.

Flexibilidade: refere-se ao espaço físico não fixo; o ritmo, pois dependerá mais do discente estabelecer este ritmo; apoio às aulas e o tempo, que também é uma variável dependente do cotidiano do aluno.

Formação permanente e pessoal: o atendimento das necessidades acontece por meio de atividades formativas ou não; o aluno é um ser ativo que desenvolve sua iniciativa, atitudes, interesses, valores e disciplina; superação do nível cultural de cada discente e capacidade técnica para o mercado. Eficácia: o discente elabora seu cronograma de estudo e, assim, tem seu ritmo de aprendizagem respeitado; os conteúdos selecionados e elaborados por especialistas da área especificam com a adequada utilização do recurso multimídia; comunicação bidirecional frequente de forma a garantir o processo de ensino-aprendizagem.

Economia: permite a redução de custos em relação ao sistema presencial, pois diminui gastos de locomoçáo do aluno para aperfeiçoamento e faltas no ambiente de trabalho para ocasionais cursos de formação em nível de pós-graduação e, principalmente, estabelece a economia de escala.
\end{abstract}

As desvantagens e/ou limitaçóes no processo de $\mathrm{EaD}$ apresentadas podem ser analisadas pelos seguintes fatores, de acordo com Landim (1997, p. 36):

Interatividade: o processo de socialização deixa muitas lacunas, pois a interação pessoal de alunoprofessor não alcança os objetivos propostos;
Emocional: pouca interação denota um relacionamento sem afetividade, tornando o modelo um processo frio sem a preocupação no indivíduo, no companheirismo;

Experiência: a falta de contato impossibilita a troca de experiência do professor-aluno e alunoprofessor, e a abertura de um espaço para discussão das respectivas realidades e posterior discussão para formação de opinióes críticas;

Feedback: o retorno, embora se utilize de modernas tecnologias, não atende à necessidade do aluno em tempo hábil;

Unicidade: no que se refere à confecção do material impresso, este sempre é elaborado de uma única forma e trabalhado para diversas realidades. Deixa-se de lado o incentivo, a criatividade, a espontaneidade, a expressáo das ideias do aluno;

Compreensáo textual: alguns cursos necessitam que seus alunos tenham um bom nível de compreensão de textos e que saibam manusear os recursos de multimídia;

Avaliação: o processo de avaliação realizado a distância apresenta muitas falhas, não sendo confiável;

Acompanhamento: a primazia pela qualidade requer um acompanhamento constante e o que afeta esta ideia é a busca desenfreada por quantidade, isso afeta a estrutura do curso, ocasionando abandonos, deserçóes ou fracassos;

Custos e serviços: embora se estabeleça uma economia de escala e tendo um custo reduzido com este processo em relação ao sistema tradicional, sua implantação requer altos investimentos. Os serviços administrativos apresentam-se de forma muito complexa se comparado ao tradicional.

A EaD é uma modalidade que pode contribuir em muito com o desenvolvimento educacional de qualquer comunidade e, principalmente, para a sociedade brasileira que evidencia, a cada ano, índices elevados de reprovação, abandono, evasão e analfabetismo que afetam toda uma sociedade, seja nos investimentos feitos, seja no desperdício de políticas educacionais inconsistentes.

A distância de localidades é suprimida com a ferramenta da $\mathrm{EaD}$ e sua metodologia e, embora exija muita dedicação do discente, pode elevar o nível de conhecimento da sociedade e tornar o saber uma variável includente, e não excludente, como é nos dias de hoje. 


\subsection{Aprendizagem e estratégias na EaD}

Com a dinâmica das mudanças que caracterizam o novo contexto mundial, a educação é e será o meio com o qual o indivíduo poderá contar para sobreviver e manter-se no mercado táo competitivo. $\mathrm{O}$ novo ritmo do processo de evolução almeja por ferramentas educacionais que permitam a qualificação agora e posteriormente.

As rápidas e constantes mudanças estão mostrando uma amplitude de informaçôes que se torna difícil a seleção de conteúdos para as devidas qualificações e se estes são realmente importantes para a devida clientela. Segundo Lévy (1996), hoje se evidencia uma metamorfose do funcionamento social, das atividades cognitivas e das representações de mundo.

É necessário conhecer o como fazer a educação, principalmente as várias concepçóes do conhecimento humano e da formação dos professores que refletiram suas ideias e pensamentos nos seus alunos, podendo estar ou náo relacionado com o contexto do meio de cada ator deste processo.

As preocupações com os métodos e as concepções em $\mathrm{EaD}$ vão além da verificação das características mais comuns do seu processo com a de uma determinada teoria. Essa está em construir um conceito de métodos e concepçôes que embasem os projetos de $\mathrm{EaD}$.

\section{Metodologia}

Esta pesquisa é de cunho qualitativo, sendo também caracterizada quanto à sua natureza em uma pesquisa básica. Quantos aos objetivos, foi uma pesquisa descritiva, que fez uso dos procedimentos de análise dos dados coletados em um questionário.

Para coletar os dados, foi utilizado questionário contendo 14 (quatorze) questôes, com 10 (dez) perguntas fechadas e 04 (quatro) abertas com a finalidade de identificar quais tecnologias são utilizadas ao desenvolver o currículo dos cursos EaD. Foi realizada no Polo de Educação a Distância na cidade de Gurupi, estado do Tocantins, aplicado no mês de julho de 2016. Participaram da pesquisa 05 (cinco) professores/tutores que atuam nos cursos de licenciatura em Química, Matemática, Física e Biologia.

Os dados quantitativos foram analisados por meio de estatística descritiva, para explicitar os recursos e estratégias mais citados pelos sujeitos. Os dados qualitativos foram submetidos à análise de conteúdo. Para Bardin (2011, p. 37), a análise de conteúdo consiste em:

um conjunto de técnicas de análise das
comunicaçóes. Não se trata de um instrumento,
mas de um leque de apetrechos; ou, com mais rigor,
será um único instrumento, mas marcado por uma
grande disparidade de formas e adaptável a um
campo de aplicaçáo muito vasto: as comunicaçóes.

Para Chizzotti (2006, p. 98), “o objetivo da análise de conteúdo é compreender criticamente o sentido das comunicaçóes, seu conteúdo manifesto ou latente, as significaçooes explícitas ou ocultas”.

As categorias para tal análise não foram definidas a priori, os seja, elas emergiram dos dados coletados no questionário durante a pré-análise.

\section{Análise dos resultados}

Dos cinco professores e tutores que responderam ao questionário, 3 (três) atuam na $\mathrm{EaD}$ há mais de 6 anos e 2 (dois) estão entre 1 e 2 anos.

Para verificar o impacto do uso destas tecnologias no processo de ensino nos cursos de graduação do polo da Universidade Aberta do Brasil (UAB) da cidade de Gurupi - TO, a análise foi organizada em quatro categorias: as mídias e os materiais que utiliza; o grau de importância destas mídias e materiais; a interação dos alunos por meio destas mídias; e o atendimento das necessidades das licenciaturas. 
$\mathrm{Na}$ primeira categoria, sobre as mídias e os materiais que os professores utilizam, foram trabalhadas duas questóes, uma aberta (3) e outra fechada (2).

Foram apresentadas cinco alternativas com a possibilidade de indicação de mais uma que não tivesse sido contemplada. Apresentamos o Gráfico 01 que detalha os dados coletados.

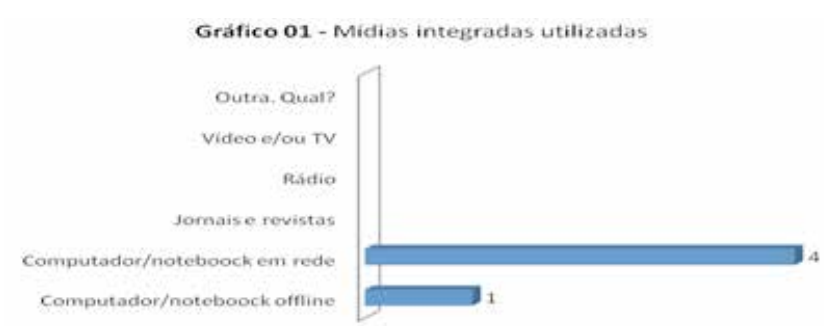

Fonte: elaborado pelo autor.

Podemos observar que $80 \%$ dos professores utilizam o computador/notebook em rede para o processo de ensino dos seus conteúdos e $20 \%$ indicaram computador/notebook off-line.

$\mathrm{Na}$ questão três foi perguntado se utilizam as salas de bate-papo, Skype, e-mail, fórum, chats, WhatsApp ou outras formas para contactar os alunos e por quê. Todos responderam que utilizam e as palavras prevalecentes nas respostas foram: praticidade e facilidade de acesso, resultados efetivos, maior interatividade, principalmente as mídias sociais, e e-mail para orientação e para sanar dúvidas.

$\mathrm{Na}$ categoria sobre o grau de importância atribuído pelos docentes, temos as questóes 7, 8, 9 e 10 que serão apresentadas em gráficos.

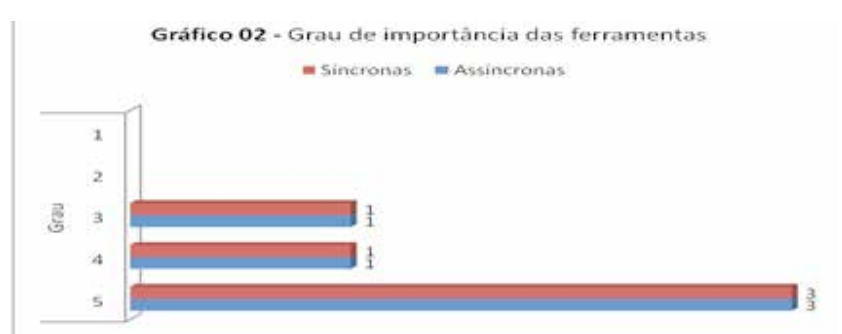

Fonte: elaborado pelo autor.
O grau de importância atribuído às ferramentas síncronas e assíncronas foi no mesmo percentual, ou seja, $60 \%$ atribuíram o maior grau (5) e $20 \%$ grau 3 e 4 para as duas ferramentas.

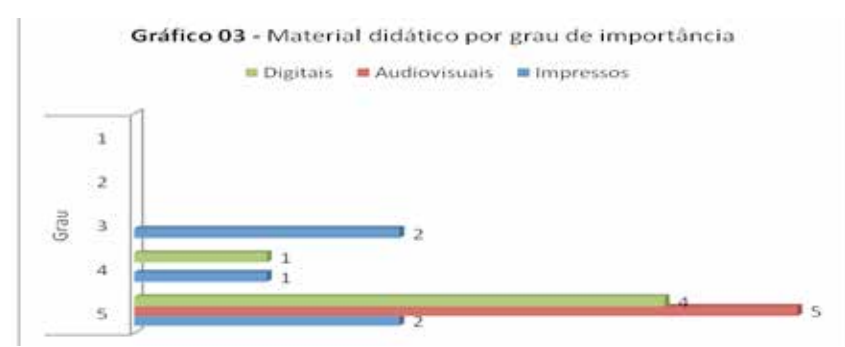

Fonte: elaborado pelo autor.

Acerca do grau de importância para o ensino e a aprendizagem nos três tipos, prevaleceram, com grau 5, os audiovisuais, seguidos dos digitais e por último os impressos, que empataram quantitativamente com o grau 3.

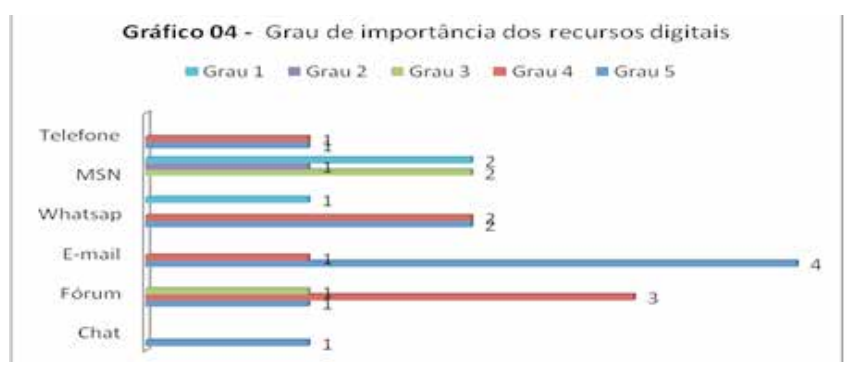

Fonte: elaborado pelo autor.

As respostas a que grau de importância atribui aos recursos digitais indicou que existe uma prevalência do e-mail, seguido do WhatsApp e depois o fórum como destaques.

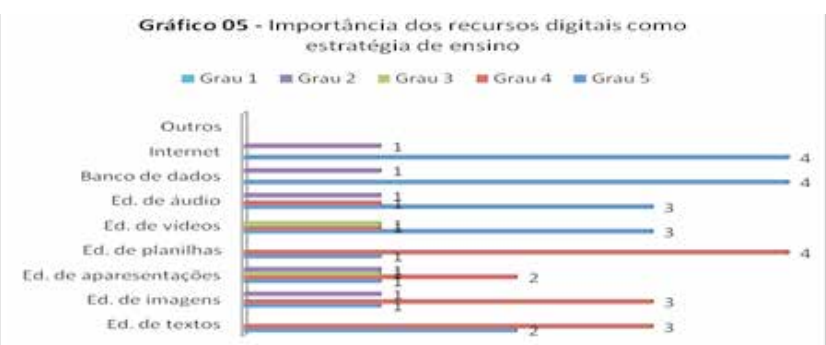

Fonte: elaborado pelo autor. 
Considerando o grau 5, temos a internet e o banco de dados, seguidos dos editores de áudio e vídeo, e com grau 4 o editor de planilhas, seguido do editor de imagens e textos.

$\mathrm{Na}$ terceira categoria, que trata da interação dos alunos por meio das mídias, temos as questóes 5, 12 e 14. A quinta questão solicita que o professor avalie a interação dos alunos com as mídias propostas nos cursos, e as palavras-chaves identificadas foram: "dificuldade dos alunos (chats e fóruns)", "satisfatória", "boa", "ocorre quando motivado e explorado pelo professor”. Na questão 12 foi atribuído $100 \%$ de grau 5 de importância em integrar as tecnologias digitais de informação e comunicação aos interesses dos alunos. Como resposta da questáo 14 , foi indicado que $80 \%$ atribuíram grau 5 e $20 \%$ grau 4 para a necessidade de os alunos dominarem as tecnologias de informação e comunicação.

$\mathrm{Na}$ última categoria, sobre o atendimento das necessidades das licenciaturas, foram as questōes 4, 6, 11 e 13. Na questáo quatro, foi perguntado quais mídias considera mais adequadas ao curso, tendo sido indicados: indicação do Moodle com alguma dificuldade de domínio das ferramentas pelos alunos; fóruns; possibilidade de videoconferência para maior interatividade na área de exatas; e computador conectado à internet. $\mathrm{Na}$ sexta questão, foi perguntado se o Moodle atende às necessidades do curso, tendo as palavras-chaves: "Não atende" (2); "atende" (3). Indicaram necessidade de complementação e videoaulas.

$\mathrm{Na}$ questão 11, foi indicado por $100 \%$ dos professores o grau 5 para a integração das tecnologias digitais de informação e comunicação no desenvolvimento dos cursos EaD. E na questão 13, foi atribuído o grau 5 por $100 \%$ dos professores para que conheçam o potencial pedagógico das TIC.

\section{CONSIDERAÇÓES FINAIS}

Essa pesquisa teve como finalidade identificar quais tecnologias são utilizadas ao desenvolver o currículo dos cursos EaD do Polo da UAB de Gurupi - TO.

$\mathrm{Na}$ categoria grau de importância atribuído pelos docentes, as ferramentas síncronas e assíncronas tiveram mesmo percentual por grau de importância. Os audiovisuais são mais valorizados, assim como a internet e o banco de dados.

$\mathrm{Na}$ terceira categoria, que trata da interaçáo dos alunos por meio das mídias, apontaram dificuldade dos alunos nos chats e fóruns, mas consideraram satisfatório e boa quando motivado e explorado pelo professor. E $100 \%$ atribuiu grau 5 de importância em integrar as tecnologias aos interesses dos alunos, enquanto $80 \%$ atribuíram grau 5 para a necessidade de os alunos dominarem as tecnologias de informação e comunicação.

A integração das tecnologias digitais de informação e comunicação no desenvolvimento dos cursos teve $100 \%$ de grau 5, assim como para a necessidade de conhecer o potencial pedagógico das TIC.

Pode-se concluir que as tecnologias disponíveis via internet tem maior alcance, assim como as redes sociais, e apontam para a necessidade de maior domínio dos alunos para as ferramentas disponíveis no AVA utilizado.

\section{The TeCHNOLOGIES USED IN THE COURSES OFFERED IN THE GURUPI - DISTANCE EDUCATION POLICY}

\section{Abstract}

This work focuses on the technologies used in the undergraduate courses, Physics, Chemistry, 
Mathematics and Biology, offered in the distance modality at the EaD Pole of Gurupi-TO, aiming at evidencing the impact of the use of these in the learning teaching process in these courses. Work was qualitative, field, with application of questionnaire and statistical analysis and content. Based on this study it is possible to identify the digital resources or tools that facilitate the interaction between the subjects are those available on the internet and social networks, but indicate the need for greater mastery of the students as the tools of Moodle. The need for greater interaction between focusing the success of teaching and consequent student learning.

Keywords: Distance education. Technology resources. Technologies.

\section{TeCNOlOgías UTILIZADAS EN LOS CURSOS OFRECIDOS EN EL POLO EDUCACIÓN A DISTANCIA - A GURUPI}

\section{Resumen}

Este trabajo se centra en las tecnologías utilizadas en los cursos de graduación, Física, Química, Matemáticas y Biología, que se ofrecen en la distancia en el Polo ODL Gurupi-A, con el objetivo de mostrar el impacto de la utilización de éstos en el proceso de aprendizaje en estos cursos. El trabajo era de naturaleza cualitativa, por supuesto, con un cuestionario y el análisis estadístico y el contenido. Sobre la base de este estudio, es posible identificar los recursos y herramientas digitales que facilitan la interacción entre los sujetos están disponibles en Internet y las redes sociales, sino que indican la necesidad de un mayor control de los estudiantes como las herramientas de Moodle. La necesidad de una mayor interacción entre centrarse en el éxito de la enseñanza y el consecuente aprendizaje de los estudiantes.

Keywords: Educación a distancia. Recursos tecnológicos. Tecnologías.

\section{REFERÊNCIAS}

ABREU, R. de A. dos S. Software educacional ou o caráter educacional do software. Revista Tecnologia Educacional. Rio de Janeiro, ano XXVI, 1998.

BARDIN, L. Análise de conteúdo. São Paulo: Edições 70, 2011.

BRASIL. Parâmetros curriculares nacionais. 1998. Disponível em <http://portal.mec.gov.br>. Acesso em 15 jul. 2016.

BRASIL. Lei n. 9394: estabelece as diretrizes e bases da educação nacional. Diário Oficial [da] República Federativa do Brasil, Brasília, 20 dez. 1996.

BELLONI, M. L. Educaçâa a distância. Campinas: Editora Autores Associados, 1999.

CHIZZOTTI, A. Pesquisa em ciências humanas e sociais. 8 . ed. São Paulo: Cortez, 2006.

DELORS, J. (Org.). Educação: um tesouro a descobrir. 4. ed. São Paulo: Cortez, 2000.

DOWBOR, L. A reprodução social. São Paulo: Vozes, 1998.

FREIRE, P. Pedagogia do oprimido. Rio de Janeiro: Paz e Terra, 1970 .

GARDNER, H. Multiple intelligences. New York: Basic Books, 1983.

LANDIM, C. M. M. P. F. Educação a distância: algumas considerações. Rio de Janeiro:[s. n.], 1997.

LÉVY, P. O que é o virtual?. Tradução Paulo Neves. São Paulo: Editora 34, 1996.

MORAES, R. A. Informática na educação. Rio de Janeiro: DP\&A, 2000. 
MORAN, J. M. Educação a distância na formação de professores: o que é um bom curso a distância? Disponível em: <http://www.tvebrasil.com.br/salto/ead/eadtxt1c.htm>. Acesso em jul. de 2016.

MOORE, M. G.; KEARSLEY, G. Distance education: a systems view. 1996, p. 2.

NISKIER, A. Educação a distância: a tecnologia da esperança. São Paulo: Loyola, 1999.

PETERS, O. Didática do ensino a distância: experiências e estágios da discussão numa visão internacional. Rio Grande do Sul: Unisinos, 2001.

Enviado em 09 de março de 2017.

Aprovado em 20 de maio de 2017. 